\title{
Interresponse Times in Serial Recall: Effects of Intraserial Repetition
}

\author{
Michael J. Kahana \\ Brandeis University
}

\author{
Joshua Jacobs \\ Massachusetts Institute of Technology
}

\begin{abstract}
The authors examined the effects of intraserial repetition on multitrial serial learning of random consonant lists, analyzing both learning rates and perfect trial interresponse times (IRTs). Lists varied along 3 dimensions: list length, presence or absence of a repeated element, and lag between repeated elements. After achieving a forward-recall criterion on a given list, participants $(N=20)$ attempted backward recall. At small lags, IRTs between the repeated elements were very short (compared with IRTs from identical positions in nonrepetition lists). At larger lags, the IRT to recall the second repeated item was substantially longer than in control lists. These results reveal a latency analogue of the Ranschburg pattern seen in accuracy data. A Ranschburg pattern was also found in participants' learning rates. These results both generalize the Ranschburg phenomenon and present further challenges to theories of serial order memory.
\end{abstract}

Analysis of response times (RTs) has been of great value in discerning the regularities of human memory (see Kahana \& Loftus, 1999, for a review). Sternberg $(1966,1969)$ demonstrated the value of RT data in studies of short-term item recognition. Although it is more difficult to measure RTs in recall tasks, these data have provided valuable constraints on memory theory (Anderson, 1981; Kahana, 1999; Nobel, 1996; Suppes, Grown, \& SchlagRey, 1966). In serial recall and free recall, participants make multiple responses. The time between these successive responses (interresponse times; IRTs) constitutes an analogue to the simple RT measure used in single-response tasks. Whereas there has long been significant interest in the study of IRTs in free recall (e.g., Kahana, 1996; Murdock \& Okada, 1970; Patterson, Meltzer, \& Mandler, 1971; Pollio \& Gerow, 1968; Pollio, Richards, \& Lucas, 1969; Rohrer, 1996; Rohrer \& Wixted, 1994; Wingfield, Lindfield, \& Kahana, 1998; Wixted \& Rohrer, 1994), researchers have only recently begun to study IRTs in serial recall (e.g., Anderson, Bothell, Lebiere, \& Matessa, 1998; Anderson \& Matessa, 1997; Dosher \& Ma, 1998; Hulme, Newton, Cowan, Stuart, \& Brown, 1999).

This article presents an extensive study of IRTs in serial recall to further examine intraserial repetition effects. In previous studies, the effects of intraserial repetition on accuracy have been well

Michael J. Kahana, Center for Complex Systems, Brandeis University; Joshua Jacobs, Department of Electrical Engineering and Computer Science, Massachusetts Institute of Technology.

This research was funded by National Institutes of Health Grants MH55687 and AG15852 to Brandeis University. We thank Steve Madigan, Ben Murdock, and members of the Computational Memory Lab for their helpful comments. We also thank Ferenc Katona, archivist of the United States Holocaust Memorial Museum, for information on the life of Pa'l Ranschburg.

Correspondence concerning this article should be addressed to Michael J. Kahana, Center for Complex Systems, Brandeis University, Waltham, Massachusetts 02454-9110. Electronic mail may be sent to kahana@volen. ccs.brandeis.edu. documented (e.g., Crowder, 1968; Crowder \& Melton, 1965; Greene, 1991; Henson, 1998; Hinrichs, Mewaldt, \& Redding, 1973; Jahnke, 1969a, 1969b, 1970, 1972, 1974; Mewaldt \& Hinrichs, 1973; Walsh \& Schwartz, 1977). In these experiments, participants studied lists of items (usually letters or digits) in which either a single item was repeated (e.g., $K L B X D B T$ ) or all items were unique (e.g., $K L B X D N T$ ). Serial position by serial position comparisons of recall probability on the repetition and norepetition lists revealed a canonical pattern of results known as the Ranschburg effect (Ranschburg, 1902; see also Kleinknecht, 1906). ${ }^{1}$ With repeated items spaced apart, participants had difficulty recalling the second presentation of the repeated element (the second "B"). When the repeated items were massed (e.g., $K L B$ $B X D T)$, participants had greater ease in recalling both repeated items. Under certain conditions, and when scored properly (see Henson, 1998), both the facilitation and impairment effects are pronounced.

Most of the theoretical interest in the Ranschburg effect stems from the finding of impaired recall of the second repeated item when the first and second repetitions are spaced apart. For example, this finding further documents the absence of associative interference effects in serial recall (cf. Chance \& Kahana, 1997; Henson, Norris, Page, \& Baddeley, 1996). Consider a simple forward chaining model in which each item is linked to the subsequent list item (e.g., $K \rightarrow L \rightarrow B \rightarrow X \rightarrow D \rightarrow B \rightarrow T$ ). In this case, the repeated item, $B$, is associated with both $X$ and $T$. Chaining theory predicts that participants have trouble recalling the items following the two repetitions because of the interference or competition between items $X$ and $T$. This prediction would also hold for bidirectional chaining models (e.g., Lewandowsky \&

\footnotetext{
' Pa'l Ranschburg (1870-1945), a Jewish Hungarian psychologist, was the founder of the Psychological Laboratory in Budapest. Many of Ranschburg's contributions are discussed in the 1929 Festschrift volume (Psychologische Studien Ranschburg Festschrift) and also in the memorial volume of Psychological Studies of the University of Budapest, Vol. 8 (1945).
} 
Murdock, 1989) and for variants of chaining theory that include compound cueing and context (e.g., Chance \& Kahana, 1997). Contrary to these theories, participants typically are not impaired in their recall of items following the repetitions (but see Wickelgren, 1965, 1966, for exceptions).

Various explanations have been offered to account for the impaired recall of the second repeated item, but two of these, response inhibition (Jahnke, 1969a) and differential guessing of repeated and nonrepeated items (Greene, 1991), have received the most attention. To explain participants' improved recall for massed repetitions (the second feature of the Ranschburg effect), most theorists assume that the two repeated items are coded as a single unit in memory and tagged as a repetition. Each of these accounts is discussed at length in the Discussion section of this article.

Our goal in the study reported here was twofold: First, we examined the generality of the Ranschburg phenomenon by studying participants' learning and recall of longer lists of symbolic items. We focused our analyses on two new dependent measures: trials-to-criterion and IRTs between successively recalled items. If the Ranschburg pattern of results appears in both of these dependent measures, then it would not only greatly extend the generality of this effect, but it would also place strong constraints on potential theoretical accounts. A second aim of our study was to test the prediction of a response inhibition account of the Ranschburg effect. After forward learning of each list, we asked participants to recall the list backwards. Examination of participants' IRTs during successful backward recall allowed us to assess whether the impairment in recalling the second repeated item in forward recall reverses on the backward test-that is, whether participants have difficulty recalling the first repeated item because the second repeated item (recalled first) has been inhibited.

To obtain reliable IRT data, we gave our participants extensive practice at the serial recall task. (Each of 20 participants learned 432 lists of consonants to a criterion of three successive perfect recalls.) We present analyses of the effect of intraserial repetition on IRTs for all perfect recall trials. In addition, we report accuracy and latency serial position effects and learning-to-learn effects.

\section{Method}

\section{Participants}

Twenty undergraduate and graduate students at Brandeis University participated in 12 sessions for payment. The first few sessions lasted about 100 min each. By the 10 th session, most participants finished a session in less than $50 \mathrm{~min}$.

\section{Design}

In each experimental session, participants learned 36 different lists of randomly arranged consonants (excluding " $Y$ ") using the study-test procedure. After each list was learned to a criterion of three successive perfect recalls in the forward direction, participants were asked to recall the list once in the reverse direction (starting from the end of the list).

The 36 lists studied in each experimental session represented a factorial of three different list lengths $(11,12$, and 13 consonants) crossed with two repetition conditions (lists with no repeats, lists with one repeated consonant). Each of these conditions had six lists. In the repeated consonant conditions, the lists were composed of six different repetition lags $(0$ [massed]-5). In these repetition lists, the position of the first repeated item was varied randomly subject to the constraint that occurrence of the repeated element was not in the first two or last two serial positions of the list. The presentation order of these list conditions was separately randomized for each participant and each experimental session.

\section{Procedure}

A personal computer controlled stimulus presentation and recorded both responses and IRTs. At the start of each trial, the computer displayed a fixation cross to signal the onset of the list items. Each consonant was then individually displayed in the center of the screen for $1 \mathrm{~s}$ followed by a 250-ms blank interstimulus interval (ISI)

Immediately following each list presentation, the computer displayed an input screen with a row of placeholders corresponding to each item in the list. As the participant typed in the list items, each typed character appeared in the appropriate placeholder. Participants were instructed to press the space bar if they were unable to remember which item belonged in a given position. To enable recording of IRTs, we did not permit participants to use the backspace key to correct their responses. After each recall attempt, the computer displayed performance measures for that trial (percentage correct and mean IRT). We instructed participants to respond as quickly as possible while maintaining high accuracy.

After attaining the criterion of three consecutive forward recalls without errors, participants were given a single backward recall test. The recall procedure was the same as with the forward recalls except that participants were instructed to recall the consonants in reverse order.

Participants were allowed to pause briefly between different lists and were encouraged to take a break at midsession. The assignment of consonants to the list structures was separately randomized for each participant and each experimental session.

\section{Results}

Results are reported separately for nonrepetition lists and repetition lists. For nonrepetition lists, we report accuracy and IRT serial position curves for forward and backward recall. For repetition lists, we used participants' IRTs to examine the effects of intraserial repetition, and in particular to see whether the Ranschburg effect, previously known for accuracy data (e.g., Henson, 1998), can also be seen using latency data. We also examined participants' rate of learning as a function of intraserial repetition.

\section{Nonrepetition Lists (Forward Recall)}

Figure 1 shows serial position curves for first trial recall, partitioned by list length for both early and late sessions of the experiment. In these and all other analyses reported in this article, serial recall was scored using a strict criterion-an item was scored as correct only if it was recalled in the correct serial position. In early sessions (left panel), participants exhibit the classic serial position curve for visually presented lists (e.g., Madigan, 1971) with a pronounced primacy effect and a small, but significant, recency effect. At late sessions (right panel), the change in the serial position curves reveals a learning-to-learn effect (e.g., Keppel, Postman, \& Zavortnik, 1968). Highly practiced participants do not show much recency in the serial recall task. These data also show how even small increases in list length lower the serial position curve.

Once participants achieved list mastery, IRTs were used to probe the structure of memory. Figure 2 plots IRTs as a function of serial position for all perfect trials. The left panel shows data from early sessions, and the right panel shows data from late 


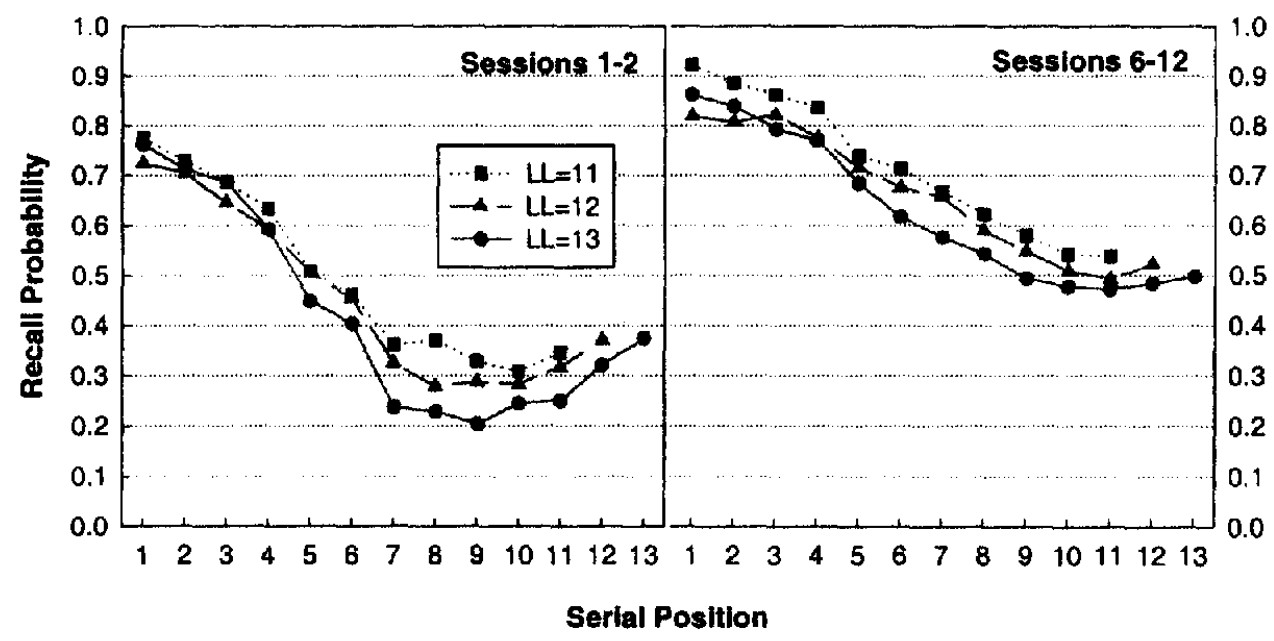

Figure 1. Recall accuracy as a function of serial position for the first forward recall attempt of nonrepetiion lists. Data are partitioned according to list length (LL). The left panel shows data from Sessions 1-2, and the right panel shows data from Sessions 6-12.

sessions. Within each panel, the IRT functions are partitioned by list length. These functions have a characteristic form that is similar for each different list length and degree of learning. Following an initial delay to recall the first item, the temporal organization of the subsequent IRTs has an overall inverted- $U$ shape, with fast IRTs at the beginning and end of the list. Within the list, the IRTs vary in a nonmonotonic fashion, suggesting that there is consistency in participants' temporal grouping. For example, a very long IRT is found between recall of Items 6 and 7, but the preceding and following IRTs are both fast. Such a pattern could emerge under a variety of simple models. For example, if participants randomly partition lists into chunks of 2,3 , and 4 items, then the probability of a new chunk at Item 7 would be .37 , as compared with .22 at Item 6 and .26 at Item 8 . Alternatively, if participants consistently divided lists into chunks of constant size, with chunk sizes of 2-4 varying across participants or lists, a new chunk would begin with Item 7 on two thirds of all lists; however, new chunks would never begin with Items 6 or 8 .

The average IRT functions shown in Figure 2 obscure significant variability across participants. Inspection of individual participant's IRT functions revealed that some participants grouped the lists in a consistent manner, with long IRTs every second, third, or fourth item. For other participants, the average IRT functions did not reveal striking grouping patterns but still showed a strong tendency for longer IRTs near the center of the list and shorter IRTs at the beginning and end of the list. This may reflect partic-

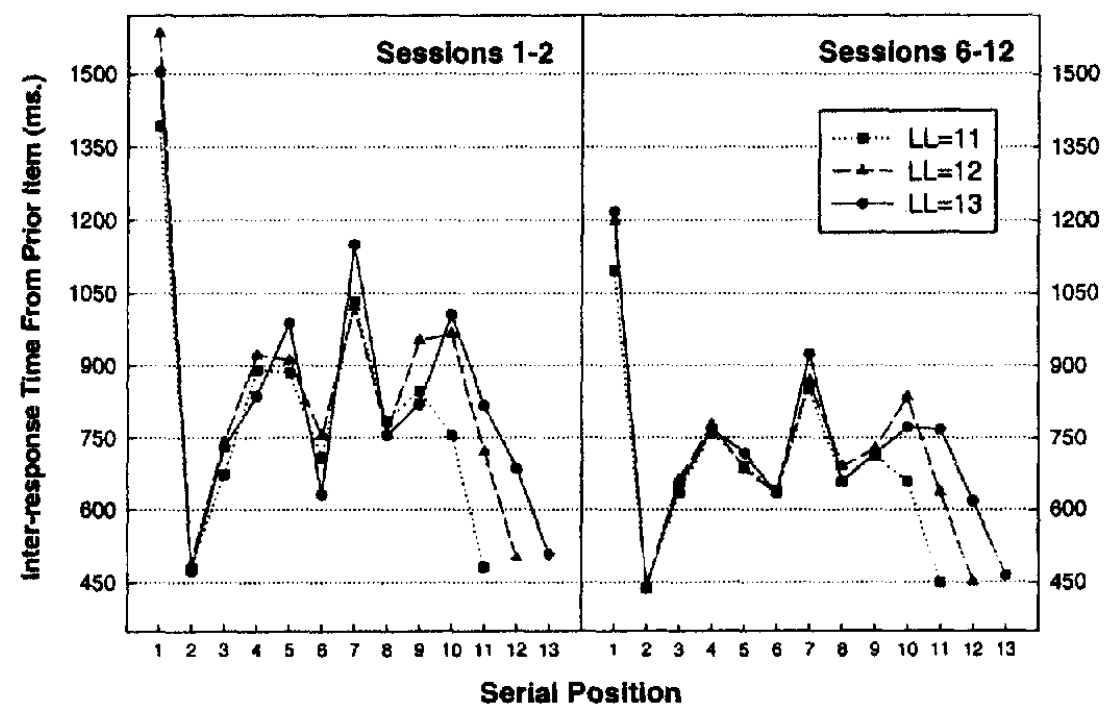

Figure 2. Interresponse times (in milliseconds) for transitions between successive serial positions. Data, shown for perfect recalls of nonrepetition lists, are partitioned by list length (LL). The left panel shows data from Sessions 1-2, and the right panel shows data from Sessions 6-12. 
ipants' formation of variable-sized chunks, which are probably influenced by list-specific consonant subsequences. In averaging across many different lists the evidence for these participants' grouping strategies would be obscured. Nearly all participants exhibited long IRTs to recall the first list item. Similar patterns of chunking have been seen in recall of digits (Anderson et al., 1998; Anderson \& Matessa, 1997), complex spatial patterns (Terrace, 1999), and the alphabet (Klahr, Chase, \& Lovelace, 1983; Scharoo, Leeuwenberg, Stalmeier, \& Vos, 1994).

\section{Nonrepetition Lists (Backward Recall)}

Figure 3 shows backward serial position curves for nonrepetition lists at early and late sessions of the experiment. Participants performed surprisingly well on the backward recall test, even in their first two sessions. The switch from mostly primacy in forward recall to mostly recency in backward recall is consistent with previous studies (e.g., Li \& Lewandowsky, 1995; Madigan, 1971).

Figure 4 shows the temporal output pattern for perfect backward recalls at early and late sessions of the experiment. Although IRTs in backward recall show greater variability than forward recall, the basic temporal organization is similar (cf. Figure 2). In early sessions (left panel), participants are slow at initiating recall and then show an inverted- $U$ shaped pattern of IRTs with alternations between fast and slow responses in the middle of the list. In later sessions (right panel), the same basic pattern obtains with one notable exception: The initiation delay, seen prominently in forward recall even at late stages of practice, is nearly absent in practiced backward recall. Although this difference between forward and backward recall could be consistent with the view that different retrieval mechanisms underlie these two behaviors ( $\mathrm{Li} \&$ Lewandowsky, 1995), the present comparison may be confounded with other factors. First, the backward recall test was given only after the series was reproduced without error three times in the forward direction. Thus, forward and backward recall are not equated for the level of participants' exposure to the list. Second, forward recall tests always followed the presentation of the list, whereas the backward test followed the last successful forward recall test.

In depicting the backward IRT data, it was not clear how to align the IRT functions for different list lengths. As shown in Figure 4, backward IRTs are aligned to correspond to the forward IRTs shown in Figure 2. This alignment according to presentation order revealed a near-perfect overlap between IRTs for different list lengths. Aligning the IRTs according to recall order would have obscured this equivalence. This suggests that chunks are defined during the forward learning process and then strongly affect the temporal organization of backward recall.

\section{Lists With Repeated Items (Forward Recall)}

In the context of this serial learning experiment we can ask whether lists with repeated items are harder or easier to learn than lists without repeated items. Figure 5 plots trials-to-criterion (excluding the three successive perfect trials) as a function of the lag between repetitions. The horizontal line indicates the mean trialsto-criterion for nonrepetition lists. Consistent with the Ranschburg effect previously documented in single-trial recall (e.g., Crowder, 1968; Henson, 1998), we find that lists with repeated items are alternatively easier and harder to master than nonrepetition lists, depending on the spacing of the repetitions. When the repeated items are massed, lists are easier to learn. At intermediate spacings (of three items) lists are harder to learn. This finding generalizes the Ranschburg effect; it suggests that participants are not merely biased against recalling the second repetition, but that it is actually more difficult to master repetition lists with moderate interrepetition spacings.

A basic feature of the Ranschburg effect is that separating repetitions of list elements produces impaired memory primarily for the second instance of the repeated element. Here we examine whether this effect, previously shown for accuracy after a single study trial, appears in participants' perfect-trial IRTs. To measure the Ranschburg effect using IRTs, we first divided each IRT by the

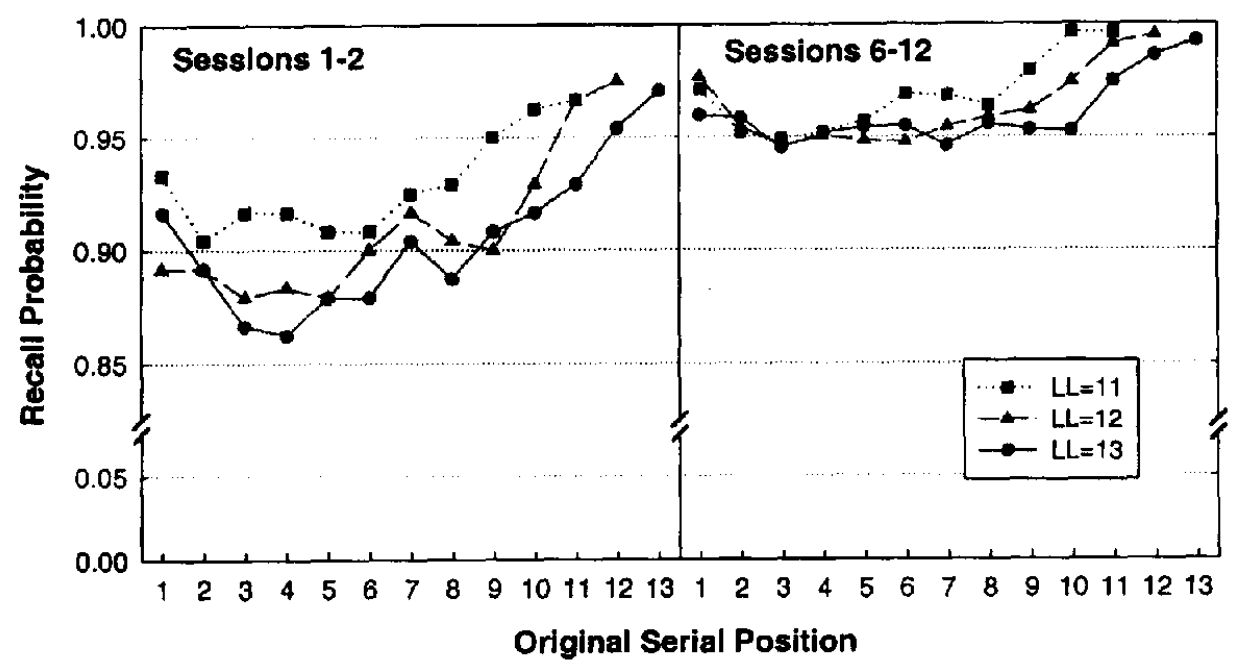

Figure 3. Serial position curve for the backward recall trial that follows the three successive perfect forward recalls. Data are shown for Sessions 1-2 and Sessions 6-12. LL = list length. 


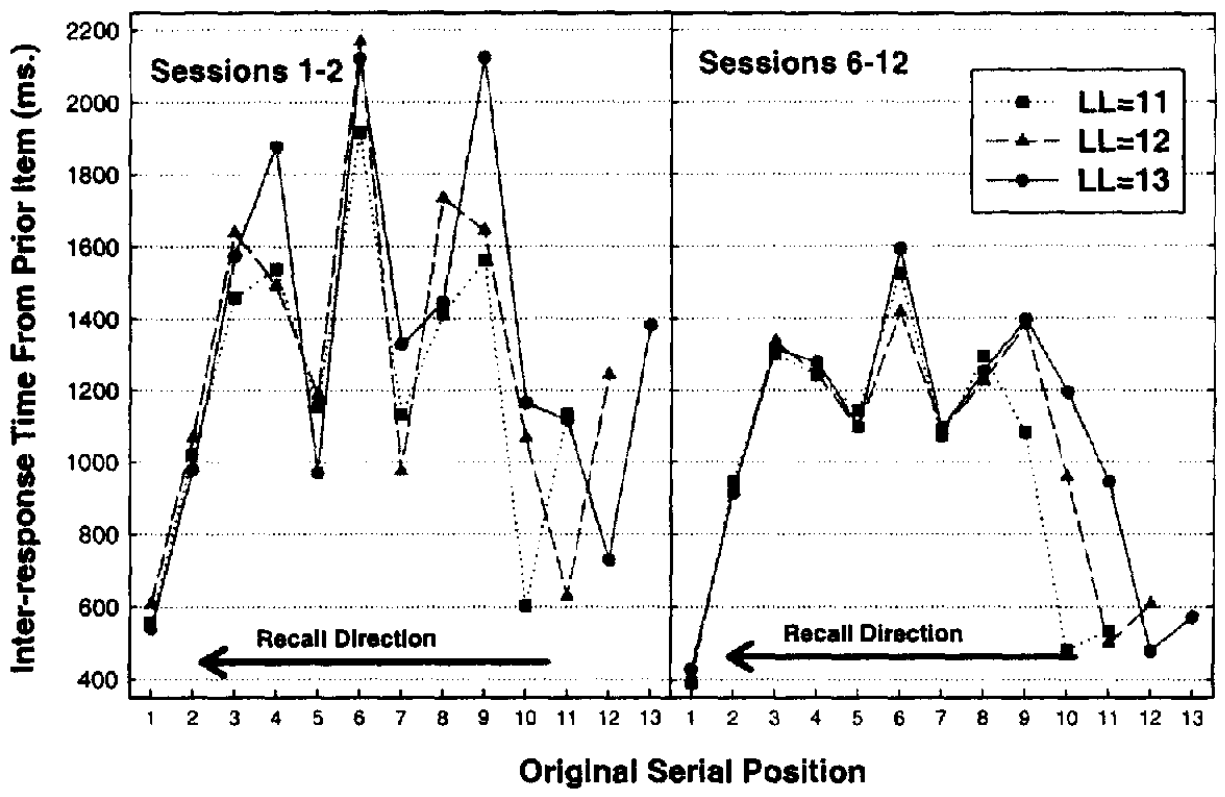

Figure 4. Interresponse times (in milliseconds) for transitions between successive serial positions. Data are shown for correct backward recall of nonrepetition lists. Data are partitioned by list length (LL). The left panel shows data from Sessions 1-2, and the right panel shows data from Sessions 6-12. Recall begins at right moves leftward.

average IRT for its list. We then analyzed IRTs at each of four critical list transitions: into $R_{1}$ (the first repeated element), out of $R_{1}$, into $R_{2}$ (the second repeated element), and out of $R_{2}$. These values were then tallied for both repetition lists and identical serial positions in nonrepetition lists. Figure 6 plots the difference between the normalized critical IRTs for repetition and nonrepetition lists. Positive values indicate impairment (slowed IRTs for repetition lists), whereas negative values indicate facilitation. Relative

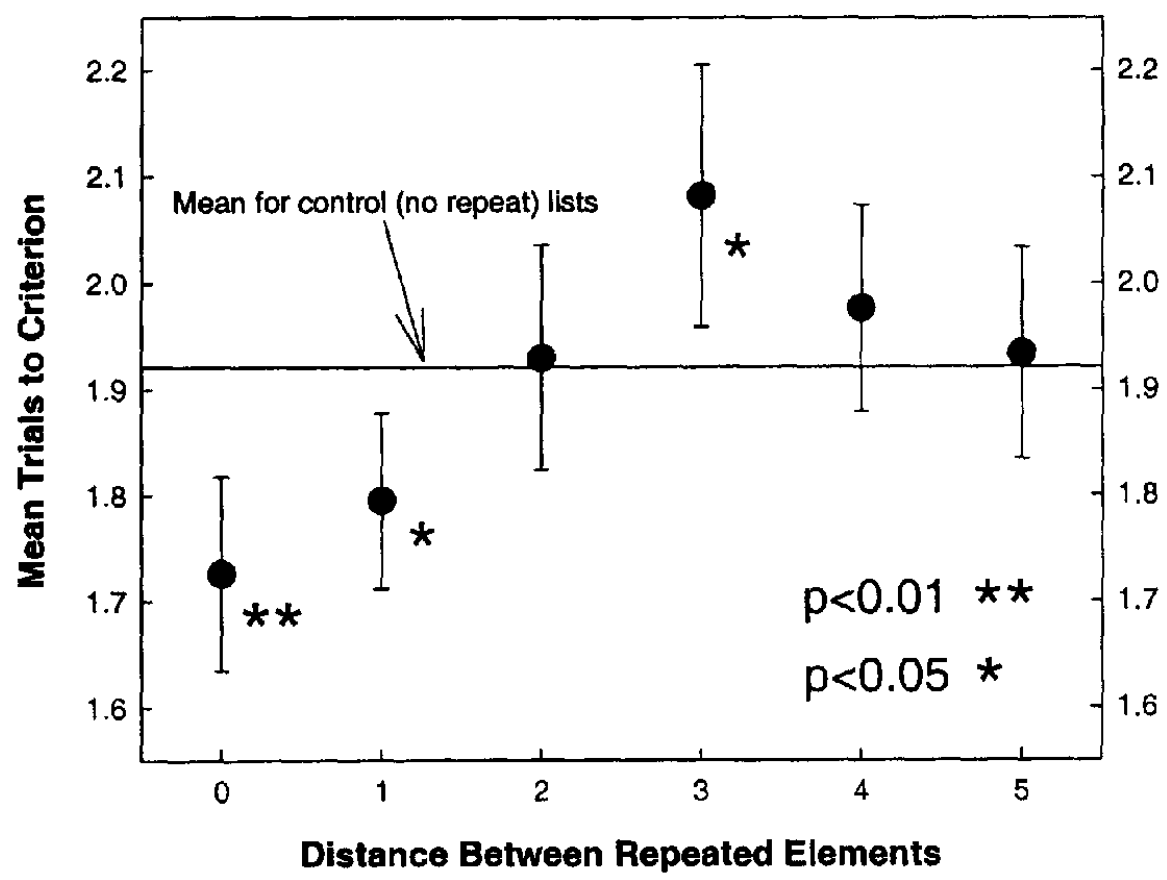

Figure 5. Trials to criterion (the number of trials prior to the three successive perfect trials) as a function of the distance between repeated items. The horizontal line indicates the average trials to criterion for nonrepetition lists. Error bars represent two standard errors around the mean. 


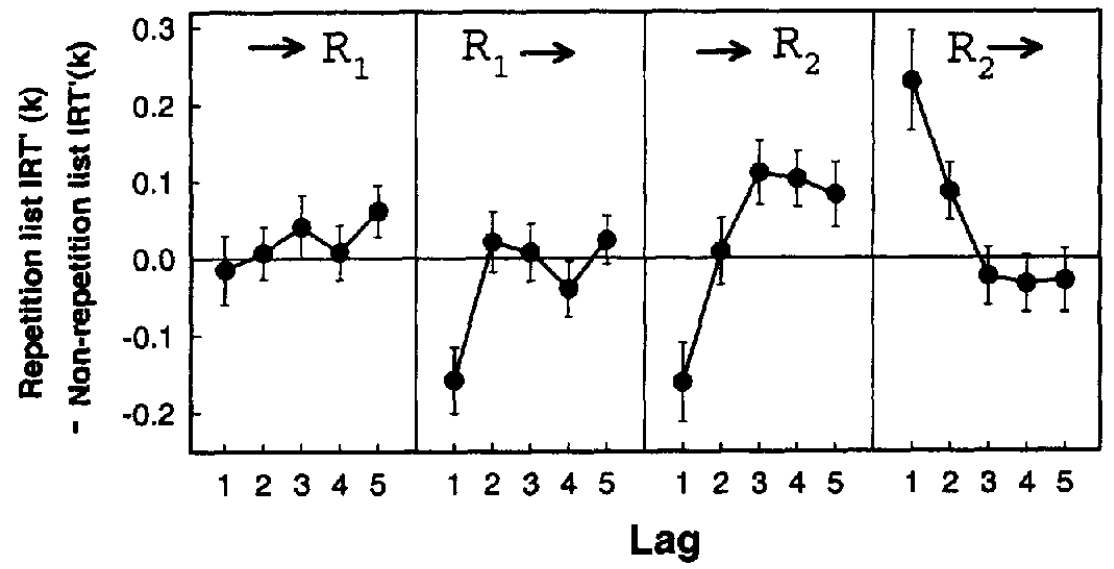

Figure 6. Inhibition-facilitation of the critical interresponse times (IRTs) as a function of interrepetition lag. The $y$-axis measures the level of impairment or facilitation as the difference between the normalized IRTs (IRT ${ }^{\prime}$ ) for the repetition and nonrepetition lists (equated for serial position). Positive values indicate impairment; negative values indicate facilitation. This IRT difference is plotted as a function of lag for all spaced repetitions (the effect of massed items is not shown in these plots because graphing their substantial facilitation effect would obscure the other significant effects plotted in this figure. For a list of consonants correctly recalled in forward order (e.g., $A \rightarrow B \rightarrow \ldots \rightarrow R_{1} \rightarrow \ldots \rightarrow R_{2} \rightarrow \ldots \rightarrow J \rightarrow K$ ), the critical transitions are into the first repeated item $\left(\rightarrow R_{1}\right)$, out of the first repeated item $\left(R_{1} \rightarrow\right)$, into the second repeated item $\left(\rightarrow R_{2}\right)$, and out of the second repeated item $\left(\mathbf{R}_{2} \rightarrow\right)$. Going from left to right, the four subplots show the impairment or facilitation for each of these transitions. The error bars represent two standard errors around the mean.

to a nonrepetition list, IRTs into $R_{2}$ were longer if the repeated elements were spaced apart in the list. Conversely, IRT's into $\boldsymbol{R}_{\mathbf{2}}$ were shorter if the repetitions were in nearby list positions. IRTs into $R_{1}$ were unaffected by the repetition (as compared with lists of nonrepeated elements). These findings, appearing consistently at each of the three final recalls, demonstrate a latency analogue of the accuracy Ranschburg effect.

These data also reveal a number of subtleties in the temporal organization of responses for nearby repetitions. For repetitions that are separated by a single element (e.g., $K L Z V B M B T X D R$ ), the IRT to recall the item following the first repetition $(M)$ is greatly facilitated, whereas the IRT to recall the item following the second repetition $(T)$ is greatly impaired (see Figure 6 ).

\section{Lists With Repeated Items (Backward Recall)}

Jahnke (1969a) suggested that the Ranschburg effect might be due to inhibition of already recalled items, an account that was favored by Ranschburg himself. This would explain participants' inability to recall the second repeated element. This would also explain why the Ranschburg effect is rarely observed when tested using cued recall (i.e., using the preceding list item to probe for recall of the repeated item). This response inhibition account is appealing because models of serial and free recall require some type of inhibitory mechanism to prevent them from repeatedly recalling the same items (e.g., Burgess \& Hitch, 1999; Lewandowsky \& Murdock, 1989; Raaijmakers \& Shiffrin, 1980).

If the IRT-Ranschburg effect reflects inhibition of recalled items, then we might expect that a backward recall test would produce a reversal of the pattern of results seen in forward recall. The panels in Figure 7, arranged according to recall order rather than study order, show the pattern of IRT facilitation and inhibition for perfect backward recalls. The overall pattern of Figure 7 looks quite similar to Figure 6: Repetition lag does not have much of an effect on the IRT into $R_{2}$ (the first recalled item). For repetitions that are separated by a single element, the IRTs out of $R_{2}$ and into $R_{1}$ are greatly facilitated, whereas the IRT out of $R_{1}$ is greatly impaired. In relation to the order of recall, this pattern is nearly identical to that seen in forward recall.

If, at lags of several items, the response inhibition account of the IRT-Ranschburg effect is correct, then we would expect the effect to flip in the backward recall phase and appear as a longer IRT into $R_{1}$ (see Figure 7, Panel 3, Lags 2-5). Although there is a hint of an effect for Lag 3 , the overall pattern of the backward recall data do not offer strong support for the response inhibition account. To more carefully evaluate the inhibition account, we binned Lags 3 through 5 , because these lags showed the largest IRT-Ranschburg effect in forward recall. For this binned measure, the normalized IRT difference was $0.100( \pm 0.037)$ for forward recall, but only $0.027( \pm 0.040)$ for backward recall; this difference was significant by a twotailed $t$ test, $t(19)=2.65, p<.02$. This failure to observe a reversal in the IRT-Ranschburg effect is inconsistent with a response-inhibition account.

The data in Panel 2 of Figure 7 suggest an alternative account of the backward recall IRTs. Perhaps the lengthened IRT into $R_{\mathbf{2}}$ seen in the forward recall phase (Panel 3 of Figure 6) reflects a weakened link between $R_{2}$ and the preceding list item. In this case, we would expect to find a lengthened IRT out of $R_{2}$ on the backward recall phase (Panel 2 of Figure 7). Although the evidence for this alternative interpretation is not particularly striking, we did observe a significant impairment at Lag $5(p<.01)$. 


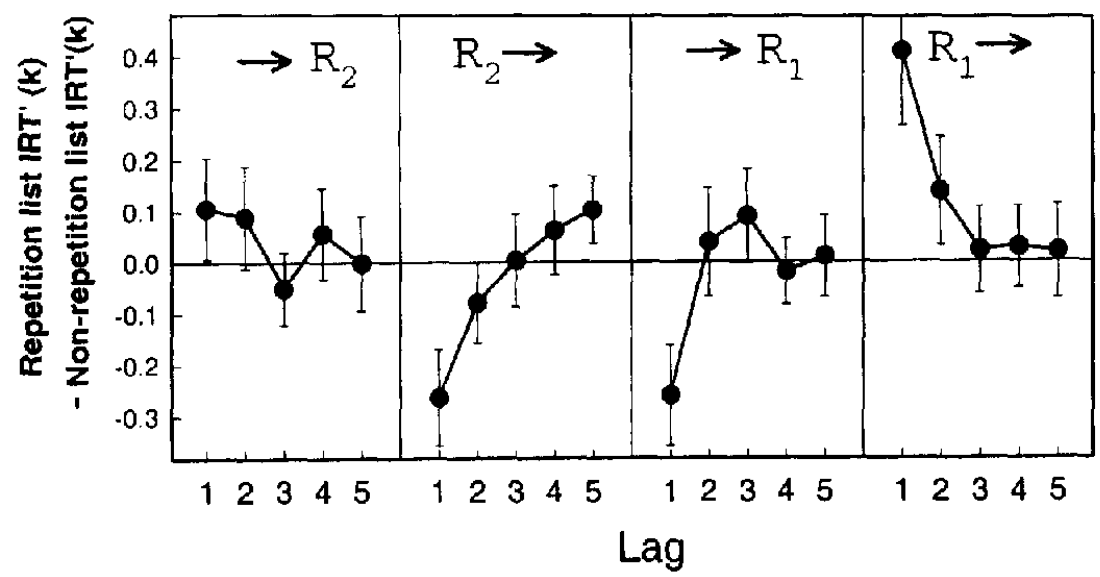

Figure 7. Inhibition-facilitation of the critical interresponse times (IRTs) for backward recall. Only perfect backward recall attempts are included in this graph. For a list of consonants correctly recalled in backward order (e.g., $\mathrm{K} \rightarrow \mathrm{J} \rightarrow \ldots \rightarrow \mathrm{R}_{2} \rightarrow \ldots \rightarrow \mathrm{R}_{1} \rightarrow \ldots \rightarrow \mathrm{B} \rightarrow \mathrm{A}$ ), the critical transitions are into the second repeated item $\left(\rightarrow R_{2}\right)$, out of the second repeated item $\left(R_{2} \rightarrow\right)$, into the first repeated item $\left(\rightarrow R_{1}\right)$, and out of the first repeated item $\left(R_{1} \rightarrow\right)$. Going from left to right, the four subplots show the impairment or facilitation for each of these transitions. The error bars represent two standard errors around the mean.

\section{Discussion}

Recent years have seen renewed interest in models of serial recall (e.g., Anderson et al., 1998; Anderson \& Matessa, 1997; Burgess \& Hitch, 1999; Chance \& Kahana, 1997; Page \& Norris, 1998), driven, in part, by the popularity of the memory span task (e.g., Baddeley, 1986; Dosher \& Ma, 1998; Hulme et al., 1999). We have long known (e.g., Harcum, 1975) that serial position curves alone cannot constrain these models. Additional benchmark findings in serial recall include positional gradients (Nairne, 1992) and the effects of experimental manipulations on the early and late portions of the serial position curve (e.g., Watkins, Watkins, \& Crowder, 1974).

The Ranschburg effect, although well documented since Crowder (1968) in the modern literature, ${ }^{2}$ has only recently been accepted as another benchmark for testing theories of serial order memory (Henson, 1998; see also Burgess \& Hitch, 1999). Interest in the Ranschburg effect stems, in part, from the challenges it poses for chaining theory and positional coding theory - the two classic frameworks for analyzing serial recall (see Young, 1968).

According to chaining theory, recall of each item is primarily cued by the immediately preceding list item (e.g., Lewandowsky \& Murdock, 1989), or, in some newer variants, by a composite representation of recently activated/recalled items (e.g., Chance \& Kahana, 1997). According to the rival positional coding hypothesis, the positions of the items in the list serve to cue each item; no item-to-item associations are required.

Chaining theory makes a clear prediction regarding the effects of repeating an item on serial recall: Recall should be impaired for the items following the repeated items, but not for the repeated items themselves - a pattern not seen in the experimental data. This prediction is a by-product of associative interference. For the list $K \rightarrow L \rightarrow B \rightarrow X \rightarrow D \rightarrow B \rightarrow T$, recalling $K$ serves as a cue for $L$, which in turn serves as a cue for $B$. Because $B$ is associated with both $X$ and $T$, cueing with $B$ prompts a competition between recall of $X$ and recall of $T$. Such competition, or associative interference, should impair performance. The clarity of this prediction, and the failure to observe this result in the data, represents yet another nail in the coffin of associative chaining models of serial order.

According to positional coding theory, a position code or time tag is associated with each list item. Let us denote the position code of the $i$-th item as $p_{i}$. As the list is presented, each item is linked (associated) with the corresponding position code. In the example above, the list would be coded as $p_{1} \leftrightarrow K, p_{2} \leftrightarrow L_{r} p_{3} \leftrightarrow$ $B_{1} p_{4} \leftrightarrow X, p_{5} \leftrightarrow D, p_{6} \leftrightarrow B, p_{7} \leftrightarrow T$. Recall begins by probing with $p_{1}$ for recall of $K$. Then $p_{2}$ probes recall of $L$, and so forth. Insofar as the effectiveness of $p_{3}$ as a cue for the first repetition of $B$ does not depend on the presence of the second repetition, this class of models does not readily accommodate the Ranschburg effect. Even sophisticated modern variants of positional coding theory (e.g., Burgess \& Hitch, 1999) have difficulties explaining the Ranschburg effect.

The Ranschburg effect poses two puzzles for memory theory: When items are repeated at short lags, recall of the repeated items is enhanced; when items are repeated at intermediate lags, recall of the second repeated item is impaired. The finding that adjacent repetitions produce superior recall is readily accommodated by any model that codes items repeated in succession as a single representation tagged with the number of times the item is repeated (e.g., Henson, 1998). We observed significant facilitation for adjacent repetitions ( $\operatorname{Lag} 0$ ) and also for repetitions separated by a single nonrepeated item (Lag 1). Facilitation at Lag 1 is observed in some studies (e.g., Crowder, 1968) but not others (Henson, 1998). Its absence has been taken to support a special tagging mechanism as the explanation for the facilitation half of the Ranschburg effect (Henson, 1998). In our study, facilitation for

\footnotetext{
${ }^{2}$ There is an extensive earlier literature on the Ranschburg effect dating back to 1902. This literature ends around the time of the World War II, and much of it remains untranslated from German and Hungarian.
} 
Lag 1 was large and could be seen both in participants' IRTs into $R_{2}$ and in our trials-to-criterion measure. One possible interpretation is that sequences of the form $R_{1} X R_{2}$ are readily coded as a single "chunk," with fast IRTs going from $R_{1}$ to $X$ and from $X$ to $R_{2}$. Consistent with this interpretation, IRTs out of $R_{2}$ are significantly slowed at Lag 1 (see Figure 6).

To explain the impairment associated with spaced repetitions, researchers have proposed two alternative accounts. According to the response-inhibition account (Jahnke, 1969a), recalled items are temporarily inhibited. This type of mechanism is used by current mathematical and neural network models to prevent the model from repeatedly recalling items that have already been recalled (e.g., Burgess \& Hitch, 1999; Lewandowsky \& Murdock, 1989; Raaijmakers \& Shiffrin, 1980).

The backward test used in the study reported in this article was designed to test this response inhibition account. If recalled items are inhibited, then the Ranschburg effect should flip from the second repeated element to the first repeated element on a backward test. This predicted reversal was not observed.

Greene (1991) suggested that a guessing strategy might account for the Ranschburg impairment. Many Ranschburg experiments use lists consisting of 8 to 10 digits. With a list of 10 digits, the participant knows exactly which elements are on the list. The task, then, is to learn the positions of those elements. For lists of 8 or 9 digits there is very little uncertainty over the set of items in the list-the main uncertainty is over the assignment of items to serial positions. $^{3}$

Suppose that participants tend to guess when they are uncertain of the correct response. These guesses are more frequent as performance declines toward the end of the list. Because the set of items is pretty much known, and only a single element is repeated, it makes sense to guess an item from the set that was not already recalled. This benefits performance for all of the nonrepeated items. Because the second repeated item is usually near the end of the list, where poor memory performance encourages guessing, recall of that element shows greatest impairment relative to the control list. Greene (1991) tested this guessing hypothesis by either encouraging participants to guess liberally or instructing them not to guess at all. When encouraged to guess liberally, the impairment side of the Ranschburg effect was enhanced; when guessing was strongly discouraged, the impairment side of the Ranschburg effect was eliminated.

In the present study it is unlikely that guessing strategies contributed significantly to the Ranschburg effect. By using lists drawn at random from a set of 20 consonants, participants were faced with considerable uncertainty over which consonants would appear in a given list. Suppose, for example, that participants correctly recalled the first 7 items of a 10-item list without repetitions. If that list consisted of digits, then guessing the remaining nonrecalled digits would yield an average of one correct response (of 3 ). With lists sampled from the 20 consonants, the same strategy would yield far poorer results-average recall would be boosted by less than one fourth of a correct response.

\section{Conclusions}

This study examined the effects of intraserial repetition on learning rates and perfect trial IRTs in serial recall. We used the analysis of IRTs and learning rates in an attempt to significantly generalize the Ranschburg effect, an effect that had only been previously documented in experiments that measure accuracy for single-trial recall of short lists. In particular, we hypothesized that IRTs might reveal an effect of associative interference, originally reported by Wickelgren $(1965,1966)$ using response accuracy, but not replicated in subsequent studies. This hypothesis was motivated by findings that $\mathrm{RT}$ can reveal interference effects that are not detected by accuracy measures (e.g., Kahana, 1999; Sanders, Whitaker, \& Cofer, 1974; Waugh, 1970). In our data, IRTs revealed no significant inhibition related to associative interference. Instead, IRTs demonstrated slowed recall of the second repeated item at long lags and fast recall of the second repeated item at short lags. This basic pattern mimics the finding of facilitation and inhibition seen in accuracy data: At short lags, the repeated items are more likely to be recalled, and at long lags the repeated items are less likely to be recalled.

In analyzing serial learning of supraspan (11-13 item) lists, we generalized the Ranschburg effect to a learning measure: the number of trials participants required to reach a criterion of three successive errorless recalls. Again, we observed facilitation at short lags and impairment at intermediate lags (see Figure 5). We also show that the Ranschburg effect, previously documented with accuracy data, has an analogue in IRT data. The feature of the Ranschburg effect that has attracted the most interest is the reduced probability of participants recalling the second repeated item when repetitions are spaced. This result is often explained in terms of participants' tendency to not "guess" already recalled items, or to inhibit them. These explanations are unlikely accounts of the trials-to-criterion Ranschburg effect or the IRT-Ranschburg effect.

In summary, we obtained a pattern of results quite similar to the Ranschburg effect both for trials-to-criterion and participants' IRTs at the point of list mastery. Whereas the Ranschburg effect was thought to be a questionable result in the 1970s [Murdock, 1974, referred to it as "the Ranschburg (non) Effect," p. 297], this and other recent work (e.g., Henson, 1998) show that the phenomenon is a benchmark of serial recall, and thus, models of serial order memory should be evaluated, in part, on their ability to explain this pattern of results.

\footnotetext{
${ }^{3}$ In some studies using consonants as list items (e.g., Crowder, 1968), all of the items were sampled from a fixed set of 12 consonants.
}

\section{References}

Anderson, J. R. (1981). Interference: The relationship between response latency and response accuracy. Journal of Experimental Psychology: Human Learning and Memory, 7, 326-343.

Anderson, J. R., Bothell, D., Lebiere, C., \& Matessa, M. (1998). An integrated theory of list memory. Journal of Memory and Language, 38 , 341-380.

Anderson, J. R., \& Matessa, M. (1997). A production system theory of serial memory. Psychological Review, 104, 728-748.

Baddeley, A. D. (1986). Working memory, Oxford, England: Clarendon Press.

Burgess, N., \& Hitch, G. J. (1999). Memory for serial order: A network model of the phonological loop and its timing. Psychological Review, $106,551-581$

Chance, F. S., \& Kahana, M. J. (1997). Testing the role of associative 
interference and compound cues in sequence memory. In J. Bower (Ed.), Computational neuroscience: Trends in research (pp. 599-603). New York: Plenum Press.

Crowder, R. G. (1968). Intraserial repetition effects in immediate memory Journal of Verbal Learning and Verbal Behavior, 7, 446-451.

Crowder, R. G., \& Melton, A. W. (1965). The Ranschburg phenomenon: Failures of immediate recall correlated with repetition of elements within a stimulus. Psychonomic Science, 2, 295-296.

Dosher, B. A., \& Ma, J. J. (1998). Output loss or rehearsal loop? Outputtime versus pronunciation-time limits in immediate recall for forgetting matched materials. Journal of Experimental Psychology: Learning, Memory, and Cognition, 24, 316-335.

Greene, R. L. (1991). The Ranschburg effect: The role of guessing strategies. Memory \& Cognition, 19, 313-317.

Harcum, E. R. (1975). Serial learning and paralearning: Control processes in serial acquisition. New York: Wiley.

Henson, R. (1998). Item repetition in short-term memory: Ranschburg repeated. Joumal of Experimental Psychology: Learning, Memory, and Cognition, 24, 1162-1181.

Henson, R., Norris, D., Page, M., \& Baddeley, A. (1996). Unchained memory: Error pattems rule out chaining models of immediate serial recall. The Quarterly Journal of Experimental Psychology, 49A. 80115.

Hinrichs, J. V., Mewaldt, S. P., \& Redding, J. (1973). The Ranschburg effect: Repetition and guessing factors in short-term memory. Journal of Verbal Leaming and Verbal Behavior, 12, 64-75.

Hulme, C., Newton, P., Cowan, N., Stuart, G., \& Brown, G. (1999). Think before you speak: Pauses, memory search, and trace redintegration processes in verbal memory span. Journal of Experimental Psychology: Learning, Memory, and Cognition, 25, 447-463.

Jahnke, J. C. (1969a). Output interference and the Ranschburg effect. Journal of Verbal Learning and Verbal Behavior, 8, 614-621.

Jahnke, J. C. (1969b). The Ranschburg effect. Psychological Review, 76, 592-605.

Jahnke, J. C. (1970). Probed recall of strings that contain repeated elements. Joumal of Verbal Leaming and Verbal Behavior, 9, 450-455.

Jahnke, J. C. (1972). The effects of intraserial and interserial repetition on recall. Journal of Verbal Learning and Verbal Behavior, 11, 706-716.

Jahnke, J. C. (1974). Restrictions on the Ranschburg effect. Journal of Experimental Psychology, 103, 183-185.

Kahana, M. J. (1996). Associative retrieval processes in free recall. Memory \& Cognition, 24, 103-109.

Kahana, M. J. (1999). Associative symmetry and memory theory. Manuscript submitted for publication.

Kahana, M. J., \& Loftus, G. (1999). Response time versus accuracy in human memory. In R. J. Sternberg (Ed.), The nature of cognition (pp. 322-384). Cambridge, MA: MIT Press.

Keppel, G., Postman, L., \& Zavortnik, B. (1968). Studies of learning to learn: VIII. The influence of massive amounts of training upon the learning and retention of paired-associate lists. Journal of Verbal Learning and Verbal Behavior, 7, 790-796.

Klahr, D., Chase, W. G., \& Lovelace, E. A. (1983). Structure and process in alphabetic retrieval. Journal of Experimental Psychology: Leaming, Memory, and Cognition, 9, 462-477.

Kleinknecht, H. (1906). The interference of optical stimuli. Harvard Psychological Studies, 2, 299-308.

Lewandowsky, S., \& Murdock, B. B. (1989). Memory for serial order. Psychological Review, 96, 25-57.

Li, S., \& Lewandowsky, S. (1995). Forward and backward recall: Different retrieval processes. Joumal of Experimental Psychology: Leaming, Memory, and Cognition, 21, 837-847.

Madigan, S. (1971). Modality and recall order interactions in short-term memory for serial order. Journal of Experimental Psychology, 87, 294296.
Mewaldt, S. P., \& Hinrichs, J. V. (1973). The Ranschburg effect: Stimulus variables and scoring criterion. Memory \& Cognition, 1, 177-182.

Murdock, B. B. (1974). Human memory: Theory and data. Potomac, MD: Erlbaum.

Murdock, B. B., \& Okada, R. (1970). Interresponse times in single-trial free recall. Journal of Verbal Learning and Verbal Behavior, 86, 263267.

Nairne, J. S. (1992). The loss of positional certainty in long-term memory. Psychological Science, 3, 199-202.

Nobel, P. A. (1996). Retrieval processes in recognition and cued recall. Unpublished doctoral dissertation, Indiana University.

Page, M. P. A., \& Norris, D. (1998). The primacy model: A new model of immediate serial recall. Psychological Review, 105, 761-781.

Patterson, K. E., Meltzer, R. H., \& Mandler, G. (1971). Inter-response times in categorized free recall. Journal of Verbal Learning and Verbal Behavior, 10, 417-426.

Pollio, H. R., \& Gerow, J. R. (1968). The role of rules in recall. American Journal of Psychology, 81, 303-313.

Pollio, H. R., Richards, S., \& Lucas, R. (1969). Temporal properties of category recall. Journal of Verbal Learning and Verbal Behavior, 8. $529-536$.

Raaijmakers, J. G. W., \& Shiffrin, R. M. (1980). SAM: A theory of probabilistic search of associative memory. In G. H. Bower (Ed.), The psychology of learning and motivation: Advances in research and theory (Vol. 14, pp. 207-262). New York: Academic Press.

Ranschburg, P. (1902). Uber hemmung gleichzeitiger reizwirkungen. Zeitschrift für Psychologie und Physiologie der Sinnesorgane [On inhibition of simultaneous stimulus effects], 30, 39-86.

Rohrer, D. (1996). On the relative and absolute strength of a memory trace. Memory \& Cognition, 24, 188-201.

Rohrer, D., \& Wixted, J. T. (1994). An analysis of latency and interresponse time in free recall. Memory \& Cognition, 22, 511-524.

Sanders, A. F., Whitaker, L., \& Cofer, C. N. (1974). Evidence for retroactive interference in recognition from reaction time. Journal of Experimental Psychology, 102, 1126-1129.

Scharroo, J., Leeuwenberg, E., Stalmeier, P. F. M., \& Vos, P. G. (1994). Alphabetic search: Comment on Klahr, Chase, and Lovelace (1983). Journal of Experimental Psychology: Learning, Memory, and Cognition. 20, 234-244.

Stemberg, S. (1966). High-speed scanning in human memory. Science, 153, 652-654.

Sternberg, S. (1969). Memory-scanning: Mental processes revealed by reaction-time experiments. American Scientist, 57, 421-457.

Suppes, P., Grown, G., \& Schlag-Rey, M. (1966). A model for response latency in paired-associate learning. Journal of Mathematical Psychology, 3, 99-128.

Terrace, H. S. (in press). The comparative psychology of serially organized behavior. In S. Fountain, J. H. Danks, \& M. K. McBeth (Eds.), Biomedical implications of model systems of complex cognitive capacities. New York: Sage.

Walsh, M. F., \& Schwartz, M. (1977). The Ranschburg effect: Tests of the guessing-bias and proactive interference hypotheses. Journal of Verbal Learning and Verbal Behavior, 16, 55-68.

Watkins, M. J., Watkins, O. C., \& Crowder, R. G. (1974). The modality effect in free and serial recall as a function of phonological similarity. Journal of Verbal Learning and Verbal Behavior, 13, 430-447.

Waugh, N. C. (1970). Associative symmetry and recall latencies: A distinction between learning and performance. Acta Psychologica. 33 , 326-337.

Wickelgren, W. A. (1965). Short-term memory for repeated and nonrepeated items. Quarterly Journal of Experimental Psychology, I7, $14-25$.

Wickelgren, W. A. (1966). Associative intrusions in short-term recall. Journal of Experimental Psychology, 72, 853-858. 
Wingfield, A., Lindfield, K. C., \& Kahana, M. J. (1998). Adult age differences in the temporal characteristics of category free recall. Psychology and Aging, 13, 256-266.

Wixted, J. T., \& Rohrer, D. (1994). Analyzing the dynamics of free recall: An integrative review of the empirical literature. Psychonomic Bulletin and Review, 1, 89-106.

Young, R. K. (1968). Serial learning. In T. R. Dixon \& D. L. Horton (Eds.),
Verbal behavior and general behavior theory (pp. 122-148). Englewood Cliffs, NJ: Prentice-Hall.

Received December 14, 1998 Revision received February 16,2000 Accepted February 29, 2000

\section{Call for Nominations}

The Publications and Communications Board has opened nominations for the editorships of Journal of Applied Psychology, Journal of Consulting and Clinical Psychology, Journal of Educational Psychology, Psychological Bulletin, and Journal of Personality and Social Psychology: Interpersonal Relations and Group Processes for the years 2003-2008. Kevin R. Murphy, PhD, Philip C. Kendall, PhD, Michael Pressley, $\mathrm{PhD}$, Nancy Eisenberg, $\mathrm{PhD}$, and Chester $\mathrm{A}$. Insko, $\mathrm{PhD}$, respectively, are the incumbent editors.

Candidates should be members of APA and should be available to start receiving manuscripts in early 2002 to prepare for issues published in 2003 . Please note that the P\&C Board encourages participation by members of underrepresented groups in the publication process and would particularly welcome such nominees. Self-nominations are also encouraged.

To nominate candidates, prepare a statement of one page or less in support of each candidate and send to

- Margaret B. Spencer, PhD, for the Journal of Applied Psychology

- Donna M. Gelfand, PhD, and Lucia Albino Gilbert, PhD, for the Journal of Consulting and Clinical Psychology

- Lauren B. Resnick, $\mathrm{PhD}$, for the Journal of Educational Psychology

- Janet Shibley Hyde, PhD, and Randi C. Martin, PhD, for Psychological Bulletin

- Sara B. Kiesler, PhD, for JPSP: Interpersonal Relations and Group Processes address:

Address all nominations to the appropriate search committee at the following

[Name of journal] Search Committee

c/o Karen Sellman, P\&C Board Search Liaison

Room 2004

American Psychological Association

750 First Street, NE

Washington, DC 20002-4242

The first review of nominations will begin December 11, 2000 . 